\title{
Intra-firm Specialization, Income Distribution, and International Trade
}

\author{
Haiwen Zhou \\ Old Dominion University
}

\begin{abstract}
The impact of international trade on a firm's degree of specialization and income distribution is studied in a general equilibrium framework in which firms engage in oligopolistic competition. International trade increases a firm's degree of specialization, but the number of goods a country produces may not change. Trade may lower the welfare of the scarce factor of production. Sufficient conditions for a country's welfare to increase with trade are provided.
\end{abstract}

- JEL classification: F12

- Keywords: Degree of specialization, Income distribution, International trade, Oligopolistic competition, Increasing returns to scale

\section{Introduction}

It is well known that one benefit of international trade comes from increased degree of specialization. In the literature, it is usually implicitly assumed that each firm produces only one product. As a firm always produces one product, there is no room to study how a firm's degree of specialization changes with trade. Also, there is no distinction between a country's degree of specialization and a firm's degree of specialization: An increase of specialization means that a country produces fewer goods and freer trade leads countries to become more specialized in production. To provide a microfoundation of how countries' pattern of specializa-

\footnotetext{
*Corresponding address: Department of Economics, Old Dominion University, Norfolk, VA 23529, USA. Phone: 1- 757-683-5785, E-mail: hzhou@odu.edu.

(C2006-Center for International Economics, Sejong Institution, All Rights Reserved.
} 
tion is determined, it is interesting to study how a firm's degree of specialization changes with international trade.

This paper studies the impact of international trade on a firm's degree of specialization and income distribution in a general equilibrium framework in which firms engage in oligopolistic competition. In this model, each firm produces multiple goods. A firm's degree of specialization is modeled as the number of goods it produces. The higher the number of goods a firm produces, the lower the level of specialization. ${ }^{1}$ With the opening of trade, it is shown that a firm will become more specialized while a country still produces the same number of goods. This result is consistent with Redding's (2002) observation as he shows that there is no evidence of an increase in European countries' overall degree of specialization since 1970.

Casual observation of the demonstrations against trade and globalization reveals that international trade is also associated with income distribution effects. In this model, as trade changes the ratio of the two factors of production, it has income distribution effects. When the benefit from specialization dominates the impact from different factor endowments, the scarce factor of production benefits from trade. In the case that the scarce factor loses from trade, it is possible that a country's total welfare as measured by the aggregate utility decreases with trade. Sufficient conditions for a country's welfare to increase with trade are provided.

One feature of this model is that firms engage in oligopolistic competition. In this article, oiligopolistic competition allows a more detailed and richer study of firms' behavior, such as the choice of the degree of specialization and the level of output. While Brander (1981) pioneers in studying trade based on oligopolistic competition, he does not study how a firm's degree of specialization changes with trade.

The balance of the paper is organized as follows. Section 2 studies a consumer's maximization problem and a firm's maximization problem when each country is in autarky. These maximization conditions, the market clearing conditions, and the free entry condition form a system of equations determining an equilibrium. In Section 3, the welfare implications of international trade are studied. Section 4 discusses some assumptions of this paper and concludes.

\footnotetext{
${ }^{1}$ Young (1928) provides an illustration about the tradeoff between fixed and marginal costs of production. From his point of view, a company with a higher level of output is more likely to use more specialized machines in production as the fixed costs of machines can be spread to a higher level of output. Yang and $\mathrm{Ng}$ (1998) provide a survey of the literature on a firm's specialization. The tradeoff between fixed and marginal costs is also explored in Hansen and Jorgensen (2001) and Zhou (2004). A related line of literature in business economics is the literature on the "focusing firms", such as Porter (1990).
} 


\section{The Model}

There are two countries: home and foreign. Each country has two industries: industry 1 and industry 2 . Each country is endowed with two kinds of labor: type 1 labor and type 2 labor. For $i=1,2$, type $i$ labor can be used to produce any industry product, but it cannot be used to produce any product in the other industry. ${ }^{2}$ The number of workers in industry is $i$ denoted by $L_{i}$. Each worker supplies one unit of labor inelastically.

Following Dornbusch et al. (1977), it is assumed that each industry produces an infinite number of goods or products indexed by a number within $[0,1] .^{3}$ Thus, the number of goods produced in an industry is exogenously given. Goods in the same industry are produced by the same production technology. In this paper, each good is produced by multiple firms. The number of firms producing the same product is determined by the zero profit condition. ${ }^{4}$ When multiple firms produce the same product, they engage in Cournot competition. For an industry $i$ product, let $m_{i}$ denote the number of firms producing this product.

This section studies the situation in which each country is in autarky. It focuses on the home country as the analysis for the foreign country is similar. It focuses on a symmetric equilibrium. In a symmetric equilibrium, for goods in the same industry, the number of firms producing each good will be the same. The production quantity of each good will be the same. Firms in the same industry will have the same degree of specialization. In addition, consumers supplying labor in the same industry will have the same consumption bundle.

First, a consumer chooses the consumption quantity of each product to maximize utility. For a worker in the home country and $r, s \in[0,1]$, let $c_{i}^{1, r}$ denote an industry $i$ worker's consumption of the $r$ th product in industry 1 and $c_{i}^{2, s}$ denote this consumer's consumption of the $s$ th product in industry 2. Let $\theta$ denote a constant and $0<\theta<1$. This consumer's utility function is specified as

\footnotetext{
${ }^{2}$ See Jones (1971) and Samuelson (1971) for illustrations of specific-factor models.

${ }^{3}$ The motivation of having an infinite number of goods in an industry is that this makes the factor market competitive even though a firm may have market power in the goods market.

${ }^{4}$ This is different from models based on monopolistic competition in which each good is produced by only one firm and the number of goods (or number of varieties) is determined by the zero profit condition.
} 


$$
U=\theta \int_{0}^{1} \ln c_{i}^{1, r} d r+(1-\theta) \int_{0}^{1} \ln c_{i}^{2, s} d s .^{5}
$$

As firms make a profit of zero in equilibrium, a consumer only has wage income. Let $w_{i}$ denote the nominal wage rate paid to industry $i$ workers. Let $p_{1, r}$ denote the price of the $r$ th product in industry 1 and $p_{2, s}$ denote the price of the $\mathrm{s}$ th product in industry 2 . For a worker supplying labor in industry $i$, the budget constraint is

$$
\int_{0}^{1} p_{1, r} c_{i}^{1, r} d r+\int_{0}^{1} p_{2, s} c_{i}^{2, s} d s=w_{i}
$$

For $i, j=1,2$, let $c_{i}^{j}$ denote an industry worker's consumption of industry $j$ product. Let $p_{i}$ denote the price of an industry $i$ product. In a symmetric equilibrium, for goods in the same industry, a worker's quantity of consumption and the price are the same. Thus, $c_{1}^{1}=c_{i}^{1, r}$ and $p_{1, r}=p_{1}$ for $r \in[0,1]$. Also, $c_{1}^{2}=c_{2}^{2, s}$ and $p_{2, s}=p_{2}$ for $s \in[0,1]$. For the utility function specified in (1), a consumer's utility maximization leads to a fixed percentage of income spent on each industry. For an industry 1 worker, this worker spends $\theta w_{1}$ on purchasing industry 1 products. As the price of industry 1 products is $p_{1}$, this worker's quantity demanded of industry 1 products is $c_{1}^{1}=\frac{\theta w_{1}}{p_{1}}$. Since this worker spends $(1-\theta) w_{1}$ on industry 2 products and the price of industry 2 products is $p_{2}, c_{1}^{2}=\frac{(1-\theta) w_{1}}{p_{2}}$. Similarly, for an industry 2 worker, this worker's quantity demanded for the two products is $c_{2}^{1}=\frac{\theta w_{2}}{p_{1}}$, and $c_{2}^{2}=\frac{(1-\theta) w_{2}}{p_{2}}$.

Second, a firm's profit maximization is studied. It is assumed that a firm may produce different products within a given industry and it may not produce products belonging to different industries. A firm's degree of specialization is modeled as the number of goods it produces. Let $n_{i}$ denote the number of goods produced by a firm in industry $i$. The higher the value of $n_{i}$, the lower the degree of specialization. When a firm chooses its degree of specialization, it faces a tradeoff between the fixed cost and the marginal cost of production. Let $f_{i}\left(n_{i}\right)$ denote an industry $i$ firm's total fixed cost of producing $n_{i}$ products denoted in labor units. It is assumed

\footnotetext{
${ }^{5}$ One special feature of this type of utility function is that a consumer's elasticity of demand is minus one. This feature is useful in simplifying presentation but is not necessary for deriving main results in this paper. A general utility function is studied in Zhou (2004).
} 
that $f_{\dot{i}}^{\prime}>0$. That is, the total fixed cost of producing $n_{i}$ products increases as $n_{i}$ increases. However, the fixed cost of production for each product $f_{i} / n_{i}$ decreases as increases. Let $\beta_{i}\left(n_{i}\right)$ denote an industry $i$ firm's marginal cost of production denoted in labor units. It is assumed that $\beta_{\mathrm{i}}^{\prime}>0$. That is, the marginal cost of production for each good increases as $n_{i}$ increases. One illustration of this assumption on costs is that for a more specialized technology, workers need more training. The fixed cost of training is high, but trained workers are more productive than untrained workers. Thus, a technology using more trained workers has a higher fixed cost of production, but a lower marginal cost of production.

Let $x_{i}$ denote an industry $i$ firm's quantity of production. A firm's revenue from one product is $p_{i} x_{i}$ and total revenue from the $n_{i}$ products is $n_{i} p_{i} x_{i}$. A firm's total cost is $\left(f_{i}+\beta_{i} n_{i} x_{i}\right) w_{i}$. As a result, a firm's profit is $n_{i} x_{i} p_{i}-f_{i} w_{i}-n_{i} \beta_{i} x_{i} w_{i}$. Each firm takes the wage rate as given and chooses the degree of specialization $\left(n_{i}\right)$ and the quantity of each good $\left(x_{i}\right)$ to maximize its profit. The first order condition of profit maximization with respect to $n_{i}$ is

$$
p_{i} x_{i}-f_{\mathrm{i}}^{\prime} w_{\mathrm{i}}-\left(\beta_{\mathrm{i}}^{\prime} n_{\mathrm{i}}+\beta_{i}\right) x_{i} w_{i}=0, i=1,2
$$

From (3), the following second order condition is necessary for a firm's profit maximization and is assumed to be satisfied,

$$
f_{\mathrm{i}}^{\prime \prime}+\left(2 \beta_{\mathrm{i}}^{\prime}+\beta^{\prime \prime} n_{\mathrm{i}}\right) x_{i}>0 .
$$

The first order condition of profit maximization with respect to $x_{i}$ is

$$
p_{i}+x_{i} \frac{\partial p_{i}}{\partial x_{i}}=\beta_{i} w_{i}, i=1,2 .
$$

The left-hand side of (5) is the marginal revenue and the right-hand side is the marginal cost. Equation (5) states that marginal revenue is equal to marginal cost when a firm chooses its output optimally.

Third, with free entry and exit of firms, each firm makes a profit of zero in equilibrium. The zero profit condition is

$$
n_{i} x_{i} p_{i}-f_{i} w_{i}-n_{i} \beta_{i} x_{i} w_{i}=0, i=1,2 \text {. }
$$

Fourth, labor market needs to be cleared. Because each firm produces $n_{i}$ goods and there are $m_{i}$ firms producing each good, the total number of firms in industry $i$ 
is $\frac{m_{i}}{n_{i}}$. Each firm needs $f_{i}+\beta_{i} n_{i} x_{i}$ units of labor, and the total demand for industry $i$ labor is $\frac{m_{i}\left(f_{i}+\beta_{i} n_{i} x_{i}\right)}{n_{i}}$. The total supply of labor in industry $i$ is $L_{i}$. Clearance of the labor market for industry $i$ workers leads to

$$
\frac{m_{i}}{n_{i}}\left(f_{i}+\beta_{i} n_{i} x_{i}\right)=L_{i}, i=1,2 .
$$

Finally, goods market needs to be cleared. Both industry 1 and industry 2 workers have demand for a firm's product. The total demand for an industry $i$ product is $L_{i} c_{i}^{i}+L_{j} c_{j}^{i}$. The total supply of this product is $m_{i} x_{i}$. Clearance of the goods market of an industry $i$ product leads to

$$
L_{i} c_{i}^{i}+L_{j} c_{j}^{i}=m_{i} x_{i}, i=1,2
$$

This leads to

$$
\begin{gathered}
\theta\left(w_{1} L_{1}+w_{2} L_{2}\right)=p_{1} m_{1} x_{1}, \\
(1-\theta)\left(w_{1} L_{1}+w_{2} L_{2}\right)=p_{2} m_{2} x_{2} .
\end{gathered}
$$

In the Appendix, it is shown that a firm's elasticity of demand is given by

$$
\frac{\partial x_{i}}{\partial p_{i}} \frac{p_{i}}{x_{i}}=-m_{i}
$$

Plugging (10) into (5) yields

$$
p_{i}\left(1-\frac{1}{m_{i}}\right)=\beta_{i} w_{i}
$$

Equation (11) is the usual formula that a firm's price is a markup over the marginal cost of production. In equation (11), a firm's price decreases with the number of firms producing the same product $\left(m_{i}\right)$.

Equations (3), (6)-(7), (9a), (9b), and (11) form a system of ten equations. These equations define ten variables $n_{1}, n_{2}, x_{1}, x_{2}, w_{1}^{r}, w_{2}^{r}, m_{1}, m_{2}$ and $p_{2}$. One equation is redundant from Walras's Law. An equilibrium is a vector $\left(n_{1}, n_{2}, x_{1}, x_{2}, w_{1}^{r}, w_{2}^{r}, m_{1}, m_{2}, p_{1}\right.$, and $p_{2}$ ) satisfying these equations.

In this following, by eliminating some variables, the above system of ten equations is simplified to a system of two equations. We begin this process by defining the 
normalized wage rate for industry $i$ as

$$
w_{i}^{r} \equiv \frac{w_{i}}{p_{i}}
$$

With this normalization, equations (3), (6), and (11) change to

$$
\begin{gathered}
x_{i}-f_{\mathrm{i}}^{r} w_{i}^{r}-\left(\beta_{\mathrm{i}}^{\prime} n_{i}+\beta_{i}\right) x_{i} w_{i}^{r}=0 . \\
n_{i} x_{i}-f_{i} w_{i}^{r}-n_{i} \beta_{i} x_{i} w_{i}^{r}=0 . \\
1-\frac{1}{m_{i}}=\beta_{i} w_{i}^{r} .
\end{gathered}
$$

Equations (12) and (13) lead to

$$
w_{i}^{r}=\frac{f_{i}-n_{i} \mathrm{f}_{\mathrm{i}}}{\beta_{i} f_{i}+\beta_{i}{ }^{\prime} n_{i} f_{i}-n_{i} \beta_{i} \mathrm{f}_{\mathrm{i}}^{\prime}}
$$

Differentiation of this equation with respect to $n_{i}$ yields

$$
\frac{d w_{i}^{r}}{d n_{i}}=-\frac{f_{i}\left[\mathrm{f}_{\mathrm{i}}^{\prime \prime}+\left(2 \beta_{i}^{\prime}+\beta_{i}{ }^{\prime \prime} n_{i}\right) x_{i}\right]}{\left(f_{i}-n_{i} \mathrm{f}_{\mathrm{i}}^{\prime}\right)\left(f_{i}+n_{i} \beta_{i} x_{i}\right)} .
$$

From (4) and (15), it is clear that $d w_{i}^{r} / d n_{i}<0$. Thus, a higher degree of specialization increases the normalized wage rate.

For each industry, workers' income is equal to the value of output as firms earn a profit of zero: $p_{i} m_{i} x_{i}=w_{i} L_{i}$. Thus, equations (9a) and (9b) yield

$$
\frac{w_{1} L_{1}}{w_{2} L_{2}}=\frac{\theta}{1-\theta}
$$

Equation (16) states that the ratio of the income of the two sectors is equal to the ratio of the percentage of income spent on the two sectors.

The price ratio between the two industries is defined as $p \equiv p_{1} / p_{2}$. Equation (16) changes to

$$
p w_{1}^{r} L_{1}=\frac{\theta}{1-\theta} w_{2}^{r} L_{2} .
$$

Manipulation of equation (13) yields 


$$
w_{i}^{r}=\frac{n_{i} x_{i}}{f_{i}+\beta_{i} n_{i} x_{i}}
$$

Plugging the value of $m_{i}$ from (7) and the value of $w_{i}^{r}$ from (18) into (14) yields

$$
R_{1} \equiv f_{i} n_{i} L_{i}-\left(f_{i}+\beta_{i} n_{i} x_{i}\right)^{2}=0
$$

Plugging (18) into (12) yields

$$
R_{2} \equiv f_{1}-n_{i} f_{i}^{\prime}-\left(n_{i}\right)^{2} \beta_{i}^{\prime} x_{i}=0
$$

Equations (19a) and (19b) define a system of two equations for two variables $n_{i}$ and $x_{i}$ as functions of the exogenous variable $L_{i}$.

\section{The Impact of International Trade}

In this section, the implications of international trade are studied. It is assumed that there is no transportation cost in international trade. The opening of international trade does not change the number of goods produced in any industry. Consumers in the foreign country have the same preferences as consumers in the home country. Firms in the foreign country have access to the same production technology as domestic firms. The only difference between the foreign country and the home country is that the two countries have different factor endowments. Suppose, for the foreign country, there are $L_{2}$ workers in industry 1 and $L_{1}$ workers in industry 2 . The opening of international trade increases the amount of labor for each industry. With trade, each industry has $L_{1}+L_{2}$ workers.

What are the implications of this change of labor endowment? First, the following proposition shows that a firm's production of each good in its production set and its degree of specialization both increase with the opening of international trade.

Proposition 1: With the opening of international trade, (i) $x_{i}$ increases; (ii) $n_{i}$ decreases.

Proof: Total differentiation of equations (19a) and (19b) with respect to $n_{i}, x_{i}$, and $L_{i}$ yields 


$$
\left|\begin{array}{ll}
\frac{\partial R_{1}}{\partial n_{i}} & \frac{\partial R_{1}}{\partial x_{i}} \\
\frac{\partial R_{2}}{\partial n_{i}} & \frac{\partial R_{2}}{\partial x_{i}}
\end{array}\right|\left|\begin{array}{l}
d n_{i} \\
d x_{i}
\end{array}\right|=\left|\begin{array}{c}
-\frac{\partial R_{1}}{\partial L_{i}} d L_{i} \\
0
\end{array}\right| .
$$

For $\Delta \equiv \frac{\partial R_{1}}{\partial n_{i}} \frac{\partial R_{2}}{\partial x_{i}}-\frac{\partial R_{1}}{\partial x_{i}} \frac{\partial R_{2}}{\partial n_{i}}$, it is the determinant of the coefficient matrix. For stability, it is assumed that $\Delta<0$.

(i) Application of Cramer's rule leads to

$$
\frac{d x_{1}}{d L_{i}}=-\frac{\partial R_{2}}{\partial n_{i}} \frac{\partial R_{1}}{\partial L_{i}} / \Delta
$$

From (19a), it can be shown that $\frac{\partial R_{1}}{\partial L_{i}}>0$. From (19b), it can be shown that $\frac{\partial R_{2}}{\partial n_{i}}<0$, and $\frac{\partial R_{2}}{\partial X_{i}}<0$ Thus, $d x_{i} / d L_{i}>0 .^{6}$

(ii) Application of Cramer's rule leads to

$$
\frac{d x_{i}}{d L_{i}}=\frac{\partial R_{2}}{\partial x_{i}} \frac{\partial R_{1}}{\partial L_{i}} / \Delta
$$

Thus, $d n_{i} / d L_{i}<0$.

Q.E.D.

The intuition behind Proposition 1 is the following. With the opening of trade, the total number of consumers in each industry increases. As a result, each consumer receives a lower share of a firm's output. If a firm's output is fixed, its marginal revenue from the last unit of a consumer's consumption increases. As the marginal revenue is higher than the marginal cost, a firm's quantity of production of each good increases. As a higher quantity is produced, a more specialized technology will be used, as the average cost of production will be eventually lower with the increase in the scale of production.

It is not obvious that international trade increases a firm's scale of production. When the number of workers in an industry increases, one possibility is that the equilibrium may be re-established through a change of $m_{i}$ proportionally and no

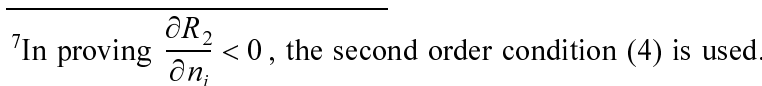


change of other variables such as $x_{i}$. This possibility is ruled out by checking equation (11). As $m_{i}$ increases (or decreases), $p_{i}$ decreases (or increases). If other variables do not adjust, a firm will have a negative (or positive) profit. Thus, other variables also need to adjust to re-establish the equilibrium. As $m_{i}$ measures the number of firms producing the same product, oligopolistic competition is essential in deriving the result that a firm's scale increases with the opening of trade.

The result that a firm's scale of production increases with international trade is supported by empirical evidence. For example, Bernard and Jensen (1999, p 23) find that at any point in time exporters produce more than twice as much output. Also, they find that exporting firms are more capital intensive (ranging from $7 \%$ to $22 \%$, p.6). As capital is related to the fixed cost of production, this empirical observation is consistent with the result that exporting firms have a higher fixed cost of production as they choose more specialized production technologies.

Second, consistent with the literature of international trade based on imperfect competition, there is no clear pattern of trade. Which country produces which product is undetermined. Also, the volume of trade is not determined.

Finally, the impact of trade on the normalized wage rates and welfare is studied. How is the normalized wage rates affected by the opening of international trade? Since $\frac{d w_{i}^{r}}{d n_{i}}<0$ and $\frac{d n_{i}}{d L_{i}}<0, \frac{d w_{i}^{r}}{d L_{i}}>0$. Thus, the normalized wage rate of each industry increases with the opening of international trade.

From (1), an industry 1 worker's welfare in autarky is

$$
U_{1}=\theta \ln \theta+(1-\theta) \ln (1-\theta)+\theta \ln w_{1}^{r}+(1-\theta) \ln w_{1}^{r} p
$$

Similarly, an industry 2 worker's welfare in autarky is

$$
U_{2}=\theta \ln \theta+(1-\theta) \ln (1-\theta)+\theta \ln \frac{w_{2}^{r}}{p}+(1-\theta) \ln w_{2}^{r} .
$$

From (17), the price ratio before trade is

$$
p=\frac{\theta w_{2}^{r} L_{2}}{(1-\theta) w_{1}^{r} L_{1}} .
$$

Let $w_{i}^{T}$ denote an industry $i$ worker's real wage rate after the opening of interna- 
tional trade. The price ratio after international trade is

$$
p^{T}=\frac{\theta w_{2}^{T}}{(1-\theta) w_{1}^{T}} .
$$

From (20a) and (21a), an industry 1 worker's utility before trade is

$$
U_{i}=\ln \theta+\theta \ln w_{1}^{r}+(1-\theta) \ln w_{2}^{r} \frac{L_{2}}{L_{1}} .
$$

Let $U_{i, T}$ denote an industry $i$ worker's utility after the opening of international trade. From (20b) and (21b), an industry 1 worker's utility with international trade is

$$
U_{1, T}=\ln \theta+\theta \ln w_{1}^{T}+(1-\theta) \ln w_{2}^{T}
$$

The following proposition shows that the abundant resource always gains from trade.

Proposition 2: If $L_{1}>L_{2}$, then an industry 1 worker always gains from trade.

Proof: Since $w_{1}^{T}>w_{1}^{r}$ and $\frac{L_{2}}{L_{1}}<1$, from (22) and (23), it is clear that the utility of an industry 1 worker increases.

The intuition behind Proposition 2 is the following. For an industry 1 worker, this worker's welfare is affected by $\frac{w_{1}}{p_{1}}$ and $\frac{w_{1}}{p_{2}}$, or $w_{1}^{r}$ and $w_{1}^{r} p$. With the opening of international trade, there are two effects on a worker's welfare. First, as the degree of specialization increases, the average cost of production for each good decreases. Thus, the normalized wage rate measured by $\frac{w_{1}}{p_{1}}$ increases. Second, as the amount of workers in each industry changes, the price ratio of industry 1 and industry 2 products $(p)$ changes. This effect is clear from (21a). From (21a), $p$ depends on the ratio $\frac{L_{1}}{L_{2}}$ since $w_{i}$ increases with $L_{i}$. An increase in the number of workers in industry 2 increases the supply of product 2 . This increases $p$ and it is beneficial to an industry 1 worker. An increase in the number of workers in industry 1 increases the demand of product 2 . This decreases $p$ and it is harmful to an industry 1 worker. For abundant workers, the effect from increased specialization and the effect from the relative price change work in the same direction. As a result, abundant workers always gain from international trade. For scarce workers, the two effects work in opposite directions. Whether a scarce worker will benefit or 
lose from international trade depends on the relative magnitude of the two effects.

The following proposition shows that everyone benefits from international trade when the two industries have the same level of labor endowment.

Proposition 3: When $L_{1}=L_{2}$, both kinds of labor benefit from international trade.

Proof: When $L_{1}=L_{2}$, for an industry 1 worker, the utility before trade is $\ln \theta$ $+\theta \ln w_{1}^{r}+(1-\theta) \ln w_{2}^{r}$. This worker's utility after trade is $\ln \theta+\theta \ln w_{1}^{T}+(1-\theta) \ln w_{2}^{T}$. For an industry 2 worker, the utility before trade is $\ln (1-\theta)+\theta \ln w_{1}^{r}+(1-\theta) \ln w_{2}^{r}$, the utility after trade is $\ln (1-\theta)+\theta \ln w_{1}^{T}+(1-\theta) \ln w_{2}^{T}$. Since $w_{i}^{T}>w_{i}^{r}$, a worker's utility increases with international trade.

Q.E.D.

The intuition behind Proposition 3 is the following. When countries are in autarky, if there are equal numbers of workers in each industry, the opening of international trade will not change the labor ratio. As a result, both kinds of labor benefit from international trade. ${ }^{7}$

Let the ratio of industry 2 workers to industry 1 workers be defined as $\phi \equiv \frac{L_{2}}{L_{1}}$. If each consumer's utility is equally weighted, the home country's welfare in autarky is $L_{1} U_{1}+L_{2} U_{2}$. The home country's welfare with trade is $L_{1} U_{1, T}+L_{2} U_{2, T}$. What's the implication of international trade on national welfare? The following proposition studies sufficient conditions for the opening of international trade to increase the domestic country's welfare. ${ }^{8}$

Proposition 4: (i) If $L_{1} \geq L_{2}$, a sufficient condition for the domestic country to benefit from trade is that $\phi<\frac{1-\theta}{\theta}$; if $L_{1}<L_{2}$, a sufficient condition for the domestic country to benefit from trade is that $\phi>\frac{1-\theta}{\theta}$. (ii) For $\theta=1 / 2$, international trade always increases a country's national welfare.

\footnotetext{
${ }^{7}$ In the case that the two countries have the same ratio of factor endowments, but one country has a larger absolute number of workers in each industry, it is clear that both the small and the large country benefit from trade. In this case, the impact of the opening of trade has an effect similar to a domestic proportional increase of both factors of production. Everyone benefits from trade.

${ }^{8}$ In the case that the scarce factor loses from trade, it is possible that a country's total welfare as measured by the aggregate utility decreases with trade. The reason of the decrease of aggregate utility is that the decrease of welfare of the scare factor of production dominates the increase of welfare of the abundant factor. Though the total quantity of consumption of each product for a country as a whole increases, the aggregate welfare decreases because of the law of diminishing marginal utility. In this case, it is always possible through redistribution from winners to losers between the two categories of labor to secure unambiguously a welfare gain of trade for a country.
} 
Proof: From (22)-(23), for the social welfare with trade to be larger than the welfare in autarky, it requires that

$$
\left(w_{1}^{r}\right)^{\theta\left(L_{1}+L_{2}\right)}\left(w_{2}^{r}\right)^{(1-\theta)\left(L_{1}+L_{2}\right)}\left(\frac{L_{2}}{L_{1}}\right)^{(1-\theta) L_{1}-\theta L_{2}}<\left(w_{1}^{T}\right)^{\theta\left(L_{1}+L_{2}\right)}\left(w_{2}^{T}\right)^{(1-\theta)\left(L_{1}+L_{2}\right)} .
$$

(i) As $w_{i}^{T}>w_{i}^{r}$, a sufficient condition for (24) to hold is that $\left(\frac{L_{2}}{L_{1}}\right)^{(1-\theta) L_{1}-\theta L_{2}}<1$. If $L_{1} \geq L_{2}, \phi<\frac{1-\theta}{\theta}$, leads to $\left(\frac{L_{2}}{L_{1}}\right)^{(1-\theta) L_{1}-\theta L_{2}}$; if $L_{1}<L_{2}, \phi>\frac{1-\theta}{\theta}$, leads to $\left(\frac{L_{2}}{L_{1}}\right)^{(1-\theta) L_{1}-\theta L_{2}}<1$

(ii) When $\theta=1 / 2,(24)$ changes to

$$
\left(w_{1}^{r}\right)^{L_{1}+L_{2}}\left(w_{2}^{r}\right)^{L_{1}+L_{2}}\left(\frac{L_{2}}{L_{1}}\right)^{L_{1}-L_{2}}<\left(w_{1}^{T}\right)^{L_{1}+L_{2}}\left(w_{2}^{T}\right)^{L_{1}+L_{2}} .
$$

Since $w_{i}^{T}>w_{i}^{r}$, a sufficient condition for (25) to be satisfied is that $\left(L_{2} / L_{1}\right)^{L_{1}-L_{2}} \leq 1$. Depending on the relative size of the work force, there are two cases. In the first case, $L_{1} \geq L_{2}$. Thus, $\frac{L_{2}}{L_{1}} \leq 1$ and $\left(L_{2} / L_{1}\right)^{L_{1}-L_{2}} \leq 1$. In the second case, $L_{1}<L_{2}$.

This leads to $L_{2} / L_{1}>1$. As a result, $\left(L_{2} / L_{1}\right)^{L_{1}-L_{2}}<\left(L_{2} / L_{1}\right)^{0}=1$. Thus (25) is always satisfied.

Q.E.D.

The two countries are not totally symmetric here as $\theta$ may not equal to $1 / 2$. Proposition 4 reveals the important roles played by the two parameters $\theta$ and $\phi$. They are important because they reflect the influence of relative demand and supply. As $\theta$ percent of income is spent on industry 1 products, an industry 1 worker's wage rate increases when $\theta$ increases. When $\phi$ increases, the opening of trade increases the supply of industry 1 workers by a larger degree, thus their welfare will be more negatively affected.

\section{Concluding Remarks}

This paper studies the impact of international trade on a firm's degree of specialization and income distribution. International trade increases a firm's degree of specialization, but the number of goods a country produces may not change. 
Trade also has income distribution effects. Sufficient conditions for a country's welfare to increase with trade are provided.

To simplify the presentation, this paper has made some special assumptions. The two effects of trade come from the increased degree of specialization and the change of the ratio of the two factors of production. These two effects are robust to some alternative assumptions. First, if the foreign country's endowment of both kinds of labor is positive but not the reverse of the home country's endowment, the opening of international trade still increases a domestic firm's degree of specialization. The reason is that as the amount of workers increases, a firm's quantity of production has to increase as the additional workers cannot be absorbed through an increase in the number of firms only. As a result, a more specialized technology will be adopted. Second, in this paper, firms producing the same product engage in Cournot competition. When firms produce differentiated products and engage in Bertrand competition, the results will be similar. Firms will still adopt more specialized technology with the opening of international trade as a more specialized technology decreases the marginal cost of production and makes a firm more competitive. Finally, in this paper, a consumer's utility function is homothetic. When the preferences are nonhomothetic, the analysis will be similar if both groups of goods are normal goods. In this case, the opening of trade increases the total quantity demanded and a firm's quantity of production. As a result, the degree of specialization increases. In all the above cases, trade may also change the ratio of the factors of production.

\section{Appendix : Derivation of the elasticity of demand of a firm (equation (10))}

For a given commodity, let $x_{-i}$ denote the total output produced by all firms other than firm $i$. Then the total supply of this product is $x_{i}+x_{-i}$. The total demand is $L_{i} c_{i}^{i}+L_{j} c_{j}^{i}$. The equalization of supply and demand yields

$$
L_{i} c_{i}^{i}+L_{j} c_{j}^{i}=x_{i}+x_{-i}
$$

For an industry $i$ worker, let $\lambda_{i}$ denote the Lagrange multiplier associated with this worker's utility maximization. An industry 1 worker's utility maximization leads to

$$
U^{\prime}\left(c_{1}^{i}\right)=\lambda_{1} p_{i} .
$$


An industry 2 worker's utility maximization leads to

$$
U^{\prime}\left(c_{2}^{i}\right)=\lambda_{2} p_{i}
$$

The utility function (1) and equations (A2a) and (A2b) lead to

$$
\begin{aligned}
& \frac{\partial c_{i}^{i}}{\partial p_{i}} \frac{p_{i}}{c_{i}^{i}}=-1, \\
& \frac{\partial c_{j}^{i}}{\partial p_{i}} \frac{p_{i}}{c_{j}^{i}}=-1 .
\end{aligned}
$$

As firms engage in Cournot competition, a firm takes other firms' output as given. Equations (9), (A1), (A3a), and (A3b) lead to

$$
\begin{aligned}
\frac{\partial x_{i}}{\partial p_{i}} \frac{p_{i}}{x_{i}} & =\left(L_{i} \frac{\partial c_{i}^{i}}{\partial p_{i}} \frac{p_{i}}{c_{i}^{i}} \frac{c_{i}^{i}}{p_{i}}+L_{j} \frac{\partial c_{j}^{i}}{\partial p_{i}} \frac{p_{i}}{c_{j}^{i}} \frac{c_{j}^{i}}{p_{i}}\right) \frac{p_{i}}{x_{i}} \\
& =-m_{i} .
\end{aligned}
$$

\section{Acknowledgements}

I thank Ingrid Bryan, Mark Lovewell, Charlie Turner, and an anonymous referee for their valuable suggestions. The usual disclaimer applies.

Received 30 August 2005, Accepted 4 April 2006

\section{References}

Bernard, A., Jensen, J. B. (1999) Exceptional Exporter Performance: Cause, Effect, or Both? Journal of International Economics, 47, 1-25

Brander, J. (1981) Intraindustry Trade in Identical Commodities, Journal of International Economics, 11, 1-14

Dornbusch, R., Fischer, S., Samuelson, P. (1977) Comparative Advantage, Trade, and Payments in a Ricardian Model with a Continuum of Goods, American Economic Review, 67, 823-839

Hansen, J., Jorgensen, G. (2001) Market Integration and Industrial Specialization on a Monopolistic Market, Journal of Economic Integration, 16, 279-298

Jones, R. (1971) A Three-Factor Model in Theory, Trade, and History, in Trade, Balance 
of Payments, and Growth (Ed.) Bhagwati, J., Jones, R., Mundell, R., Vanek, J., Amsterdam: North-Holland

Porter, M. (1990) The Comparative advantage of nations, New York: Free Press

Redding, S. (2002) Specialization Dynamics, Journal of International Economics, 58, 299-334

Samuelson, P. (1971) Ohlin was Right, Swedish Journal of Economics, 73, 365-384

Yang, X., Ng, S. (1998) Specialization and Division of Labor: A Survey, in Increasing Returns and Economic Analysis (Ed.) Arrow, K., Ng, K., and Yang, X., New York: St. Martin Press

Young, A. (1928) Increasing Returns and Economic Progress, Economic Journal, 38: 527542

Zhou, H. (2004) The Division of Labor and the Extent of the Market, Economic Theory, 24, 195-209 